\title{
MODELING CLAY-PILE INTERFACE DURING MULTI-DIRECTIONAL LOADING
}

\author{
Juan M. Mayoral' ${ }^{1}$, Juan M. Pestana ${ }^{2}$ and Raymond B. Seed ${ }^{4}$
}

\author{
${ }^{1}$ Researcher, Geotechnical Department, Institute of Engineering, National University of Mexico, Building \\ $\mathrm{N}^{\circ}$ 4, P.O. Box 04510, Mexico City, Mexico, JMayoralV@iingen.unam.mx \\ ${ }^{2}$ Associate Professor, University of California, 440 Davis Hall, Berkeley, CA 94720-1710. \\ ${ }^{3}$ Engineer Professor, University of California, 440 Davis Hall, Berkeley, CA 94720-1710.
}

\begin{abstract}
Series of multi-directional pot tests were conducted in soft clay to characterize the near field soil response during multi-directional soil-pile interaction (Mayoral et al., 2015). This experimental evidence has shown that nonlinearities associated with gapping and pile slippage during multi-directional cyclic loading of clay-pile interfaces lead to very complex force-displacement relationships. These relationships depend on the loading path and displacement history that affects the evolution of the soil stiffness. This paper introduces a simplified discrete model, which describes the variation of both the soil stiffness and lateral soil resistance of a model pile during multi-directional loading, to be used in the time domain. The model considers two limit deformation stages, and an interpolation damage like function to follow the gap evolution during the cyclic loading. The model parameters are obtained directly from uni-directional conventional p-y curves. Predictions for series of multi-directional displacement paths including circular, elliptical, figure 8 and parabolic were performed and compared to actual test data for these paths. For the cases studied, this approach is able to describe the evolution of the stiffness in the transition regime, accounting for the progressive formation of the gap around the pile, and to capture the trends, initial stiffness, peak and residual forces very closely.
\end{abstract}

KEYWORDS: clay-pile interfaces, lateral loading, piles, soil-structure interaction, soft clay behavior.

Contact person and address:

Juan M. Mayoral

COORDINACION DE GEOTECNIA

INSTITUTO DE INGENIERÍA

UNIVERSIDAD NACIONAL AUTONOMA DE MEXICO

MEXICO CITY, MEXICO
PHONE: +(52) 55 5623-3600 EXT: 8469

FAX: (510) 642-7476

E-MAIL:jmayoralv@iingen.unam.mx 


\section{Introduction}

The response of a soil-pile-structure system due to seismic loading is highly non-linear (e.g., Hadjin et al, 1992). Most of these non-linearities occur in close proximity to the pile and in the soil-pile interface, commonly referred to as the near field (e.g. Bea, 1980). Disregarding the cracking or plastic localization of the pile sections, the most important sources of this nonlinear behavior, in the near field, are the soilpile separation, gapping, soil-pile slippage, and soil degradation (or "softening"). Traditionally, these phenomena have been accounted for using concepts like the p-y and t-z curves, for lateral and vertical movements of the pile respectively. These concepts have been incorporated in continuous (e.g., Banerjee and Davis, 1978, Kaynia and Kausel, 1982), and discrete models (e.g., Kausel, 1974, Kausel et al., 1975). These models are available both in the frequency domain (e.g., Novak, 1974, 1977, Gazetas and Makris, 1991, Finn et al., 1997) and in the time domain (e.g., Matlock et al, 1978, Kagawa, 1983, Bea et al., 1984, Lok et al, 2000).

In models formulated in the frequency domain, the lateral soil resistance is commonly simulated using continuously distributed frequency dependent linear springs and dashpots excited at their support points by the free-field soil displacements, as shown in Figure 1. These models usually assume visco-elastic properties in the soil profile and frequency dependent impedance functions (e.g., Gazetas et al 1991). These impedance functions can directly account for energy radiation into the soil media. The frequency domain representation is more suited for cases where small strains are expected to occur and the loading frequency varies over a wide range (e.g. machine foundations).

Although initially the models were of discrete nature (Novak, 1974), several alternatives have been proposed to extend these formulations to continuous media. For instance, Nogami et al, (1992) developed a second-order subgrade model assuming shear coupling between distributed springs that appears to model well the response at all frequencies, including the static condition, when properly calibrated. Along the same line, Finn et al (1997) proposed a solution scheme for quasi three-dimensional soil-pile-structure interaction that uses a continuous interface element formulated in the frequency domain. This interface element has additional features such as tension cut-off and shearing failure to simulate gapping at the soil surface and yielding in the near field. However, this procedure uses the equivalent linear method, and thus can only approximately capture the nonlinearities in the far and near field. In order to enhance the performance of this formulation, the compatibility between shear strains and moduli and damping is 
enforced at selected times during shaking rather than throughout the entire shaking. Models formulated in the frequency domain, apart from the fact that they are generally developed in a more rigorous mathematical framework than time-domain models (i.e. provide a closed form solution of the boundary value problem for idealized cases using a complex stiffness), have the advantage of incorporating the radiation damping directly in the formulation. This allows a good performance of the model for a wide frequency range. However, in earthquake loading, the predominant frequency does not vary over a very large range, and is generally relatively low (i.e., less than 10Hz). Furthermore, during strong ground shaking, the hysteretic damping due to near field soil nolinearities is usually much more significant than the radiation damping under strong seismic events (Lok, 1999). For these reasons, in the state of practice, models formulated in the time domain have been preferred when a high level of deformation/displacement is expected in the different parts of the soil-foundation-structure system.

A better representation of soil nolinearities in the near field soil during strong shaking is achieved in the time domain, were the concept of p-y and t-z are used to model the soil response subjected to lateral and axial loading. Since the pioneering work of Matlock and co-workers (Matlock et al., 1978), discrete elements formulated in the time domain have been widely used to describe the soil response in the near field soil. In this type of formulation, pairs of nonlinear springs and linear dashpots are employed to represent the interface soil. Numerically, the stiffness of each nonlinear spring can be described using several elasto-plastic springs that can be arranged in series or in parallel. The configuration in parallel decreases the number the degrees of freedom and is more stable during the numerical computations (Lok et al, 2000). The stiffness of the nonlinear springs can also be approximated by a mathematical function (e.g. Kagawa and Kraft, 1981), often of hyperbolic nature, which relates the lateral strains in the nearfield soil with the corresponding stresses. However, these types of models cannot capture gapping or slippage and a more flexible approach, such as the discrete type of models, is better suited to large displacement cases.

In any case, the spring stiffness is frequency independent. Rate effects can be taking into account approximately by properly correcting the shear strength, during the construction of the p-y curve, according to the relative shearing velocity in the interface soil-pile (Lok, 1999). The hysteretic damping is introduced directly by the non-linear spring, and the radiation damping is provided by the added viscousdampers. The computation of the pile response over time is carried out with an implicit finite difference marching scheme in time algorithm.

This paper introduces a practice-oriented discrete model formulated in the time domain as an attempt to capture soil nonlinearities associated with gapping and pile slippage for multi-directional loading paths. 
The nonlinear stiffness of the spring is described in terms two limit stages, which define the initial and final deformation states, and one transition regimen. In the first stage, the gap remains closed at all times and in the final stage, the gap is completely stabilized. An interpolation damage-like function, which depends on the accumulation of plastic deformations, allows for a better representation of the gap evolution on the transition zone of the p-y curve. In this case, due to the multi-directional loading, the lateral soil resistance $\mathrm{p}$ has two orthogonal components $\mathrm{p}_{\mathrm{x}}$ and $\mathrm{p}_{\mathrm{y}}$, which corresponds to lateral displacements in the $\mathrm{x}$ and $\mathrm{y}$ directions respectively. Although radiation damping is not incorporated explicitly in the formulation, the nonlinear spring can be used in series with a dashpot to model radiation damping (i.e. geometric damping) (e.g. Lok, 1999, Lok et al., 2000).

\section{Model description}

This section introduces the key elements of a simplified numerical model proposed to simulate the behavior of soil-pile interfaces observed during series of multi-directional pot test conducted in soft clay (Mayoral et al., 2002, 2005, \& 2015), to characterize the near field soil during multidirectional loading. A pot test is a laboratory-based technique to obtain p-y curves of several soil types. In this test, a pile segment, herein after referred to as model pile, is simulated in the laboratory using a rigid bar, which is moved horizontally through the soil of interest, as depicted in figure 2 . The rotation of the rigid bar at the top is restricted to ensure that the displacement distribution is uniform with depth. Using this methodology, material specific p-y curves have been obtained for clays (Matlock 1970; Reese 1975). However, most of this work used either monotonic or cyclic loading along a single horizontal loading axis. More recently Mayoral et al., (2002, 2005, and 2015) have conducted series of cyclic multidirectional p-y tests in soft clays. In the analysis, it is assumed that the soil-pile system can be divided into segments (or units) where the displacement distribution is uniform with depth for each segment (Matlock 1962). The methodology is to be used in time domain analyses, and the spring stiffness is assumed to be frequency independent. Rate affects (i.e. the increase on the ultimate lateral soil resistance, Pult, with the increase of pile shearing velocity when moving through the soil) can be taken into account approximately, if needed, by properly correcting the shear strength according to the shearing velocity (Biscontin and Pestana, 2001). In the proposed approach, the force-displacement relationship is defined in terms of the radial relative displacements, $r$, measured with respect to the original position of the pile to the current pile position, points $\mathrm{A}$ and $\mathrm{D}$ shown in Figure 3, and the corresponding radial lateral soil resistance, $\mathrm{p}$. Both, radial lateral soil resistance and radial displacements are, in turn, decomposed into two orthogonal components $\mathrm{p}_{\mathrm{x}}-\mathrm{x}$ and $\mathrm{p}_{\mathrm{y}}-\mathrm{y}$. Based on the observation that even in multi-directional loading the response along a radial path is one-dimensional, two limit deformations states are considered (Figure 4). The initial 
deformation stage corresponds to a condition of full contact between the soil and pile during loading (i.e., no gap). The second deformation stage corresponds to a condition where the gap is fully open and stabilized (i.e., steady state). The transitions between these two limiting states are obtained by interpolating with a function (i.e. damage-like function) that depends on the accumulation of plastic deformations. Thus, a radial coordinate system is used to keep track of the relative radial displacements between the soil and the pile. This allows the formulation to follow the position of the gap at all times during the loading process, and the force " $\mathrm{p}$ " and the corresponding radial displacement, $r$, can be decomposed in two orthogonal directions, $\mathrm{p}_{\mathrm{x}}-\mathrm{x}$ and $\mathrm{p}_{\mathrm{y}}-\mathrm{y}$.

\subsection{Initial deformation State}

For the initial limiting state (Fig. 4), it is considered that the soil and the pile remain in contact at all times. Thus, nonlinearity of the force-displacement relationship is defined from normalized p-y curves. As previously mentioned, a p-y curve is the relationship between the lateral soil resistance, $\mathrm{p}$, and the corresponding lateral displacement, y. In soils this relationship is generally nonlinear, which means that the soil stiffness changes with the deformation level. In a p-y curve, it is common practice to normalize the lateral soil resistance, $\mathrm{p}$, with respect to the pile diameter $\mathrm{D}$, pile length, $\mathrm{L}$, and the soil shear strength corrected by rate effects $\mathrm{su}^{*}$ (i.e. $\mathrm{p} /\left(\mathrm{Su}^{*} \mathrm{DL}\right)$. The lateral pile displacement, $\mathrm{y}$, is normalized with respect to the pile diameter, D (i.e. y/D). The plot p/(su DL) vs y/D is called normalized p-y curve (Lok, 1999, Mayoral et al., 2002, 2005, 2015). These normalized p-y curves can be obtained experimentally, from onedimensional pot tests, or from previously proposed functions, such as those recommended by the American Petroleum Institute (1993). The American Petroleum Institute recommends that the first loading branch be represented with the following expression:

$$
\mathrm{p} / \mathrm{P}_{\mathrm{ult}}=0.5\left(\mathrm{y} / \mathrm{yc}_{\mathrm{c}}\right)^{1 / \rho}
$$

Where: $\mathrm{p}$ is the lateral soil resistance, $\mathrm{Pult}$, is the maximum lateral soil resistance, the exponent $\rho$, defines the initial slope of the p-y curve. The value of the parameter $\rho$ goes from 3 to 4 for soft and stiff clays respectively, and $\mathrm{y}_{\mathrm{c}}$ is the critical displacement obtained as $2.5 * \varepsilon_{\mathrm{c}} * \mathrm{D}$. The critical strain, $\varepsilon_{\mathrm{c}}$, is the strain that occurs at one half of the maximum deviatoric stress in laboratory undrained triaxial compression tests of undisturbed soil samples. The ultimate lateral soil resistance, $\mathrm{P}_{\mathrm{ult}}$, is obtained from the following expression:

$$
\mathrm{P}_{\mathrm{ult}} / \mathrm{su}=3+\gamma \mathrm{X} / \mathrm{su}+\mathrm{J} \mathrm{X} / \mathrm{D}
$$




\section{$\mathrm{P}_{\mathrm{ult}} / \mathrm{Su}=9$ for $\mathrm{X}$ larger or equal than $\mathrm{X}_{\mathrm{R}}$}

Where: Pult is the ultimate soil resistance; $\mathrm{Su}$ is the undrained shear strength from undisturbed clay soil samples; $\mathrm{D}$ is the pile diameter; $\gamma$ is the effective unit weight of soil; $\mathrm{J}$ is a dimensionless empirical constant with values ranging from 0.25 to 0.5 having been determined by field or laboratory testing; $\mathrm{X}$ is the depth below soil surface, and $\mathrm{X}_{\mathrm{R}}$ is the depth below the surface to bottom of reduced resistance zone (API, 1993). For a condition of constant strength with depth, $X_{R}$, is obtained as $\left(6 \mathrm{D} /\left(\gamma \mathrm{D} / \mathrm{s}_{u}+J\right)\right.$. During the implementation presented herein, this nonlinear shape of the first loading branch was achieved combining several elastic-perfectly plastic springs in parallel as suggested by Lok (1999). The parallel configuration was preferred over the configuration in series because is more stable for numerical analyses and reduces the number of degrees of freedom, increasing the overall computational efficiency of the analyses (Lok et al, 2000).

\subsection{Second Limiting Condition-Fully Stabilized Gap}

In this state, it is considered that the gap between the soil and the pile is fully open and stabilized. Two loading regimes are identified in the force-displacement relationship. An initial portion, which starts when the gap is closed and finishes when the gap is open again due to unloading from a maximum loading state. And a second portion, where the pile is sliding through the gap and only frictional forces are presented. In the initial portion the force displacement relationship is described in terms of the initial loading branch, following the same criteria used for the initial limiting condition (i.e. experimental values from generic normalized p-y curves or API recommendations).

In this limiting state, the model is driven by a relative radial displacement, $r_{\text {rel }}=R_{\text {fac. }} r_{\text {gap }}-r$, where $r$ is the current displacement of the pile, $r_{g a p}$ is the position of the gap after unloading and $\mathrm{R}_{\mathrm{fac}}$ is a correction factor for recovery of the gap. For simplicity, the unloading portion of the curve was selected to be bilinear (i.e. elastic-perfectly plastic) response. The elastic soil response immediately after unloading is defined by the expression: $\mathrm{p}=\mathrm{K}_{\mathrm{re}}\left(\mathrm{r}_{\mathrm{rev}}-\mathrm{r}\right.$ ), where $\mathrm{K}_{\mathrm{re}}$ is the slope of a properly normalize p-y curve (e.g. $\mathrm{p} /\left(\mathrm{su}^{*}\right.$.D.L) vs $\left.\mathrm{y} / \mathrm{D}\right)$ and therefore is dimensionless. The displacement $\mathrm{r}_{\mathrm{rev}}$, defines the position of the pile immediately after unloading. The unloading condition is defined by the sign of a function H(r), defined as the norm $|\mathrm{P}(\mathrm{r})-\mathrm{F}(\mathrm{r})|$, where $\mathrm{P}(\mathrm{r})$ and $\mathrm{F}(\mathrm{r})$ are vectors corresponding to the maximum pile displacement and the actual soil pile in an specific radial direction, for a given time. Thus, unloading corresponds to 
negative values of $\mathrm{H}(\mathrm{r})$ and loading conditions corresponds to values of $\mathrm{H}(\mathrm{r})$ equal to zero. In addition, to

properly define the sign of the friction cut-off during unloading, the sign of $\left|r_{\text {rev }}-r\right|$, needs to be obtained. (i.e. positive or negative friction cut-off). During unloading, both the first and second limiting stages follows the p-y shape given by the initial branch "backbone curve" previously described, and can be characterized by normalized p-y curves obtained experimentally, from one-dimensional pot tests, or from proposed functions API(1993).

The parameters needed to define these two regions can be obtained from uni-directional pot tests where the displacement amplitude and the number of cycles are large enough to generate a gap and its subsequent stabilization.

\subsection{Transitional regime}

The experimental evidence gathered during uni-directional and multi-directional pot tests carried out in previous research (Mayoral et al., 2002, 2005, and 2015) shows the existence of a transitional regime where the force-displacement response is also a function of the accumulation of plastic deformations. This transition is described by the dimensionless damage-like function, $\theta, \theta=\left(\mathrm{r}_{\text {plas }}-\mathrm{r} / \mathrm{r}_{\mathrm{plas}}-\mathrm{r}_{\mathrm{reb}}\right)$. Where, $\mathrm{r}_{\mathrm{plas}}$ and $\mathrm{r}_{\mathrm{reb}}$ are the plastic and rebound displacements, and $\mathrm{r}$ is the final displacement after each cycle respectively, (c.f. Figure 5). The dimensionless damage-like function $\theta$, goes from 0 to 1 . For initial loading, the gap is fully closed and $\theta$ has a value of zero, as the number of cycles increases, $\theta$ increases, until fully stabilization of the gap is achieved, and $\theta$ reach a value of 1 . The material parameter $\mathrm{m}$ is selected by a small parametric study to match the observed experimental data. Thus, the force-displacement relationship in the transition regime is given by $\left(1-\theta^{\mathrm{m}}\right)$ for the initial stage plus $\theta^{\mathrm{m}}$ for the final stage.

\section{Model parameters}

The simplified discrete model presented uses four input material parameters to define the transition regime and the stabilized response. These parameters are: the normalized friction, $\alpha_{f}$ (i.e. Ffric/Pult), the rebound modulus, $\mathrm{K}_{\mathrm{re}}$, the adhesion factor, $\mathrm{R}_{\mathrm{fac}}$, and a damage parameter, $\mathrm{m}$. All of these parameters are dimensionless, and are obtained directly from normalized p-y curves, as is described next. 
Parameter $\alpha_{\mathrm{f}}$ is a measure of the minimum lateral force acting on the pile when it is sliding through an existing gap, Ffric, expressed as a fraction of the ultimate lateral force, $P_{u l t}$. The parameter $\alpha_{f}$ can be found directly from the stabilized response of a normalized uni-directional p-y curve, where the lateral forces are divided by the shear strength corrected by rate effects, $\mathrm{su}^{*}$, times the pile diameter, $\mathrm{D}$, times the embedment depth, L, and the lateral displacement, $y$, is divided by the pile diameter. Previous experimental evidence (Meymand, 1998, Mayoral et al., 2002, 2005, and 2015) appears to indicate that the sliding surface occurs within the soil and not directly at the soil-pile interface for "soft" clays (of low shear strength). Thus, $\alpha_{f}$ appears to be a direct function of the undrained shear strength of the model clay and not soil/pile interface properties. For cohesive soils with higher shear strengths, the limiting shear may be the soil/pile interface value. Limited experience suggests (Mayoral et al., 2002) that for high values of $\alpha_{\mathrm{f}}$ the area enclosed by the hysteretic loop is larger (i.e more energy is dissipated). Realistic values of this parameter range from 10 to $30 \%$ for soft clays.

Parameter $\mathrm{K}_{\mathrm{re}}$, controls the elastic rebound immediately after unloading. The value of this parameter can be found directly from a normalized uni-directional p-y curve, measuring the slope of the curve in the unloading branch. For increasing values of $\mathrm{K}_{\mathrm{re}}$, the elastic rebound of the clay decreases. For most soils, $\mathrm{K}_{\mathrm{re}}$, is very close to the initial tangent stiffness, $\mathrm{k}_{\mathrm{e}}$. The expected range of values for this parameter is from 80 to 200 .

Parameter Rfac penalizes the displacement after rebound to model approximately the effect of recovery of the gap. This parameter can be found from sensitivity studies where a model prediction is calibrated against uni-directional experimental p-y curves. The model predicts that for high values of $R_{\text {fac }}$ (i.e. $1<\mathrm{R}_{\mathrm{fac}}<0.9$ ), the position of the gap is very close to the displacement after rebound. This corresponds to soil-pile interfaces with low gap recovery. For low values of $R_{f a c}$ (i.e. $0.4<R_{\text {fac }}<0.1$ ) the gap recovers (diminishes from a maximum value) and affects the final position of the gap. Therefore, with the parameter $R_{f a c}$, the position of the soil after rebound can be controlled, thus allowing for a more realistic modeling of the gap evolution during cyclic loading.

Parameter $\mathrm{m}$, is a damage parameter that controls the evolution of the p-y response in the transition regime. Values of $\mathrm{m}$ close to zero correspond to more ductile soils, where more cycles of load are needed to achieve stabilization. Similarly, high values of $\mathrm{m}$ will correspond to brittle soils, where the $\mathrm{p}-\mathrm{y}$ response stabilizes rapidly. Sensitivity studies (Mayoral et al, 2002) have shown that realistic values of this parameter range between 0.25 to 2.0 . 
The first loading branch also needs to be determined. This can be done using the load-deflection curves proposed by API for clay, or using directly discrete points $(\mathrm{p}, \mathrm{y})$ of the first branch of a representative unidirectional p-y curve.

To apply the API recommendations to find the first loading branch, three parameters need to be characterized: the critical strain, $\varepsilon_{c}$, the ultimate soil resistance, $\mathrm{P}_{\mathrm{ult}}$, and the exponent $\mathrm{p}$, as described by the API recommendations. For soft clays a value of $\varepsilon_{\mathrm{c}}$ equal to 0.020 is usually assumed, whereas for stiff clays $\varepsilon_{\mathrm{c}}$ ranges from 0.005 to 0.010 . Pult can be found as the load corresponding to the yielding state in a uni-directional p-y curve. This has been found for static conditions to vary between 8 to 12 times the undrained shear strength of the soil, except at shallow depths where failure occurs in a different mode due to limitations in overburden pressure. The parameter $\rho$ can be found from parametric studies matching the initial branch of a uni-directional p-y curve. Typical values of this parameter range from 0.3 to 0.4 for soft to stiff clays, respectively.

\section{Evaluation of the model performance}

This section illustrates the model capabilities and the procedure to determine the material parameters described before. The multi-directional pot tests described by Mayoral (2015) were used to demonstrate the model performance. The model parameters were obtained from a representative uni-directional test. These parameters were used to predict the response of the rest of the tests. The following paragraphs describe this process.

\subsection{Parameter determination}

As stated before, the proposed model uses four parameters to define the transition regime and the stabilized response. All the model parameters were found with data from test 2D858, which corresponds to a uni-directional pot test. This test had a displacement ratio, $\mathrm{A}_{\mathrm{x}}$, of 0.8 ; a loading frequency, $\mathrm{F}_{\mathrm{x}}$, of $0.1 \mathrm{~Hz}$; an undrained shear strength (determined with shear vane) corrected by rate effects, $\mathrm{su}^{*}$, of 5.75 $\mathrm{kPa}$ and a water content of $119 \%$. The parameters were obtained as described in the previous section. During sensitivity studies these parameters were varied within reasonable ranges and the predicted response was compared with the experimental data. Figure 6 shows a comparison between the predicted response from the model and the experimental data for the set of parameters that minimize the discrepancies between both. Table 1 summarizes this set of parameters. 
Using these parameters, a series of predictions of the behavior of the near field soil for uni-directional and multi-directional loading were then conducted, comparing model predictions with observed behavior in py "pot" tests.

\subsection{Model prediction}

This section presents comparisons between experimental data obtained for several uni-directional and multi-directional p-y curves, including figure-8, circular, elliptical and parabolic displacement paths. In all the figures that follow summarizing the results, a solid line shows the model prediction and a dotted line shows the experimental data. For the multi-directional pot tests discussed herein three plots are included: comparisons in both orthogonal components $\mathrm{x}$ and $\mathrm{y}$, of $\mathrm{p}_{\mathrm{x}}-\mathrm{x}$ and $\mathrm{p}_{\mathrm{y}} \mathrm{y}$ experimental and numerical curves and the corresponding displacement path in plan view.

The first multi-directional case studied corresponds to a linear trajectory oriented at 45 degrees with respect the $x$ direction. The displacement ratio was $A_{x} / D=0.4$ and the amplitude ratio, $A_{x} / A_{y}$, was equal to 1 (where $A_{x}$ and $A_{y}$ are the maximum displacement amplitudes in the $\mathrm{x}$ and $\mathrm{y}$ direction of the displacement path). The loading frequencies, $\mathrm{F}_{\mathrm{x}}$ and $\mathrm{F}_{\mathrm{y}}$ were 0.05 and $0.05 \mathrm{~Hz}$, respectively. The water content was $113 \%$, and the undrained shear strength corrected by rate effects, $\mathrm{su}^{*}$, was $3.78 \mathrm{kPa}$. Figure 7 shows a comparison between the model predictions and the experimental results. In this particular case, the response is the same in the $\mathrm{x}$ and $\mathrm{y}$ directions. As can be seen, the model predictions $p_{\mathrm{x}}-\mathrm{x}$ and $p_{\mathrm{y}}-\mathrm{y}$ are in very good agreement overall. The initial stiffness of the soil is well captured by the model, as is the stabilized response. In the transition zone, the model follows the trends satisfactorily.

Figure 8 shows a comparison between the model predictions and the experimental results for a figure- 8 displacement path. The displacement ratio, $A_{x} / D$, was 0.75 and the amplitude ratio, $A_{x} / A_{y}$, was 3 . The loading frequencies, $\mathrm{F}_{\mathrm{x}}$ and $\mathrm{F}_{\mathrm{y}}$ were 0.04 and $0.08 \mathrm{~Hz}$, respectively. The water content was $112 \%$, and the undrained shear strength corrected by rate effects, $\mathrm{su}^{*}$, was $3.82 \mathrm{kPa}$. For the displacement associated to the largest displacement, $x$, it can be seen that the model predicts very closely the first loading branch, the stabilized response and the general trend in the transition regime in each orthogonal component. For the direction along the minimum displacement direction, $y$, it can be observed that the predicted response envelopes the measured response, but slightly over predicts " $p$ " during the initial phase of each new "figure-8" loop. 
The following case presented corresponds to an elliptical displacement path (c.f. Figure 9). The displacement ratio, $\mathrm{A}_{\mathrm{x}} / \mathrm{D}$, was 0.6 , and the amplitude ratio, $\mathrm{A}_{\mathrm{x}} / \mathrm{A}_{\mathrm{y}}$, was 3 . The loading frequencies, $\mathrm{F}_{\mathrm{x}}$ and Fy were 0.05 and $0.1 \mathrm{~Hz}$, respectively. The water content was $112 \%$, and the undrained shear strength corrected by rate effects, $\mathrm{su}^{*}$, was $3.82 \mathrm{kPa}$. As can be seen, the predicted response envelopes the measured data and captures the overall behavior well. For this case in particular, there is not a true transition range. Once the pile has finished the first elliptical cycle, there is no radial increment of the load in the subsequent cycles. Thus the stabilized regime is reached after the second cycle. This complex response of the interface soil-pile to multi-directional loading for this difficult displacement path is well

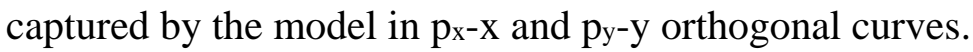

The next case studied corresponds to a circular displacement path (c.f. Figure 10). The displacement ratio, $\mathrm{A}_{\mathrm{x}} / \mathrm{D}$, was 0.6 and the amplitude ratio, $\mathrm{A}_{\mathrm{x}} / \mathrm{A}_{\mathrm{y}}$, was 1 . The loading frequencies, $\mathrm{F}_{\mathrm{x}}$ and $\mathrm{F}_{\mathrm{y}}$ were 0.05 and $0.05 \mathrm{~Hz}$, respectively. The water content was $116 \%$, and the undrained shear strength corrected by rate effects, $\mathrm{su}^{*}$, was $3.64 \mathrm{kPa}$. For this particular case the response is the same in both directions. The model again nicely envelopes the measured response. As before, there is not a true transitional zone. Again the absence of the transition zone associated with the circular trajectories is well captured during the simulation.

The final case studied corresponds to a parabolic displacement path (c.f. Figure 11). The displacement ratio, $A_{x} / D$, was 0.75 and the amplitude ratio, $A_{x} / A_{y}$, was 3 . The loading frequencies, $F_{x}$ and $F_{y}$ were 0.04 and $0.08 \mathrm{~Hz}$, respectively. The water content was 116\%, and the undrained shear strength corrected by rate effects, $\mathrm{su}^{*}$, was $3.84 \mathrm{kPa}$. Due to the anisotropy of this pile transit path, the p-y response measured in $\mathrm{x}$ and $\mathrm{y}$ is different. For the direction of maximum displacement, $\mathrm{x}$, the model is able to predict the initial deformation stage and to capture the trends of the $\mathrm{px}-\mathrm{x}$ behavior in the transition and the stabilized regime. For the shortest direction of loading, the model $p_{y}-y$ response prediction is again a nice envelope of the measured data.

In all comparisons the model captures the overall experimental data closely from the practical standpoint. For the direction associated with the maximum displacement, the model prediction is generally very good (see for instance Figure 11). For the orthogonal direction, the model provided an accurate to slightly conservative representation of the observed response. The interpolation criterion seems to capture the progressive evolution of the gap well for all cases.

This model was proposed to describe the soil-pile behavior observed in multi-directional pot tests performed in soft clay, which exhibit a particular behavior due to its strong ability to gap, which other soil types do not have. This behavior has been characterized in the laboratory through series of 
multidirectional pot tests (Mayoral et al., 2002, 2005 and 2015). For other soil type, like sands, although the force components of the lateral soil reaction under multidirectional loading are the same (i.e. frictional, dragging, and passive component), both the evolution of the lateral soil resistance and soil stiffness is different, therefore they require a different model.

\section{Conclusions}

A simplified discrete model to be used in the time domain was proposed to simulate the response observed during uni-directional and multi-directional loading of soil-pile segments. Nonlinearities associated with gapping and slippage of the pile during two-directional loading are well captured overall by the formulation. The model uses two deformation stages, and an interpolation function to follow the gap evolution during the cyclic loading. The model parameters were obtained fitting a representative unidirectional pot test. Once the parameters were thus established, predictions for a series of multidirectional displacement paths including circular, elliptical, figure 8 and parabolic were performed, and comparisons were then made to actual test data for these paths. For the cases studied, the model is able to describe the evolution of the stiffness in the transition regime, accounting for the progressive formation of the gap around the pile. The description of this transitional state is achieved with the introduction of a function that can be adjusted to better model the accumulation of plastic deformations during cyclic loading. This allows a better characterization of the energy dissipated during transient dynamic loading. Once the gap is fully open and stabilized, the model is able to describe the steady state response, including the passive component and the flat central portion of generics p-y curves reported in the literature for cyclic loading. In general, the model is able to capture the trends, initial stiffness, peak and residual forces very closely.

\section{Acknowledges}

This work was sponsored by the Pacific Earthquake Engineering Research Center through grants 2132000b and 2302001. Additional support was provided by the National Science Foundation through grant CMS-9612136.

\section{References}

American Petroleum Institute (API, 1993)."Recommended practice for planning, designing, and constructing fixed offshore platforms-working stress design," Report. RP 2A-WSD, 20th Edition, July.

Bea, R (1980). "Dynamic Response of Piles in Offshore Platfoms," in Dynamic Response of Pile Foundations: Analytical Aspects, Proc. Geotechnical Engineering Division ASCE, 80-109 
Bea, R., Litton, R., Nour-Omid, S., and Chang, J. (1984). "A Specialized Design and Research Tool for the Modeling of Near-Field Soil Interactions," Proc. 16th Offshore Technology Conf., OTC 4806, Houston, Vol. 3, 249-252.

Banerjee, P. and Davis, T. (1978) "The behavior of axially and laterally loaded single piles embedded in nonhomogeneous soils", Geotechnique, 28(3), 309-326

Biscontin, G. and Pestana, J., 2001, "Influence of Peripheral Velocity on Measurements of Undrained Shear Strength for an Artificial Soil,” Geotechnical Testing Journal, Vol. 24, No. 4, pp. 423-429.

Finn, L., Wu, G., and T. Thavaraj (1997) "Soil-Pile-Structure Interactions," in Seismic Analysis and Design for Soil-Pile-Structure Interactions, G.S.P. No 70, ASCE, 1-21.

Gazetas, G. and Makris, N. (1991) "Dynamic Pile-Soil-Pile Interaction - Part I: Analysis of Axial Vibration," Earthquake Eng. Struct. Dyn., 20(2), 115-132.

Hadjian, A. H., Fallgren, R.B., and Tufenjian, M. R., (1992). "Dynamic Soil Pile Structure Interaction.

The State of Practice," in Piles Under Dynamic Loads, G. S. P. 34, ASCE, 1-26

Kagawa, T. and Kraft, L. (1981) "Lateral Pile Response During Earthquakes," J. Geotech. Eng., ASCE, 107(12), 1713-1731.

Kagawa, T. (1983) "NONSPS (Nonlinear Response Analysis of Soil-Pile-Structure Systems): User's Manual," McClelland Engineers Inc, Houston, Texas.

Kausel, E. (1974) "Forced Vibrations of Circular Foundations on Layered Media,"

Kausel, E., Roesset, J.M., and Waas, G (1975) "Dynamic Analysis of Footings on Layered Media," Proc . ASCE, Engrg. Mech. Division, No. EM5, Oct. 1975

Kaynia, A. and Kausel, E. (1982) "Dynamic Stiffness and Seismic Response of Piles Groups," Rpt. R203, Massachusetts Inst. Of Technology, Cambridge.

Lok, T. (1999). "Numerical Modeling of Seismic Soil-Pile-Structure Interaction in Soft Clay," Ph.D. Dissertation, Univ. of California, Berkeley.

Lok, T., Pestana, J.M., and Seed, R. (2000) "Numerical Modeling of Seismic Soil-Pile-Superstructure Interaction," $12^{\text {th }}$ World Conference on Earthquake Engineering New Zealand 2000, Paper number 0914.

Matlock, H., (1962) "Correlation for design of laterally loaded piles in soft clay," A Report to Shell Development Company, Houston, Texas, Engineering Science Consultants, September 15

Matlock, H. (1970)."Correlation for design of laterally loaded piles in Soft Clay," Proc. 2nd Offshore Technology Conf., OTC 1204, Houston, Vol. 1,577-594.

Matlock, H., Foo, S.H., and Bryant, L.L. (1978) "Simulation of Lateral Pile Behavior," Proc. Earthquake Engineering and Soil Dynamics, Pasadena, CA, ASCE 600-619.

Mayoral, J. M. (2002) “Two-directional Effects in Soil Pile Structure Interaction in Soft Clay," Ph.D. Dissertation, Univ. of California, Berkeley, 2002.

Mayoral, J.M., Pestana, J.M. and Seed, R.B. (2002) "Determination of Multi-directional p-y curves for soft clays", GeoEngineering Report RCB/GE/2002-05, University of California, Berkeley, 2002

Mayoral, J.M., Pestana, J.M. and Seed, R.B. (2005) "Determination of Multi-directional p-y curves for soft clays", Geotechnical Testing Journal, Vol. 28, No. 3

Mayoral, J.M., Pestana, J.M. and Seed, R.B. (2015) "Multi-directional cyclic p-y curves for soft clays", Accepted for publication in the Journal of Ocean Engineering, Elsevier

Meymand, P. (1998) "Shaking Table Scale Model Test of Non-Linear Soil-Pile-Superstructure Interaction In Soft Clay" Ph.D. Dissertation, Univ. of California, Berkeley 
Nogami, T, Jiang-Xiong, Z, and Takayoshi I (1992) "First and Second Order Dynamic Subgrade Models For Soil-Pile Interaction Analysis," in Piles Under Dynamic Loads, Geotech. Spec. Pub. 34, ASCE, 187-205

Novak, M. (1974) "Dynamic Stiffness and Damping of Piles," Can. Geotech. J., 11(4), 574-598.

Reese, L., Cox, W., and Koop, F. (1975). "Field Testing and Analysis of Laterally Loaded Piles in Stiff Clay," Proc. 7th Offshore Technology Conf., OTC 2312, Houston, Vol. 2, 671-690. 

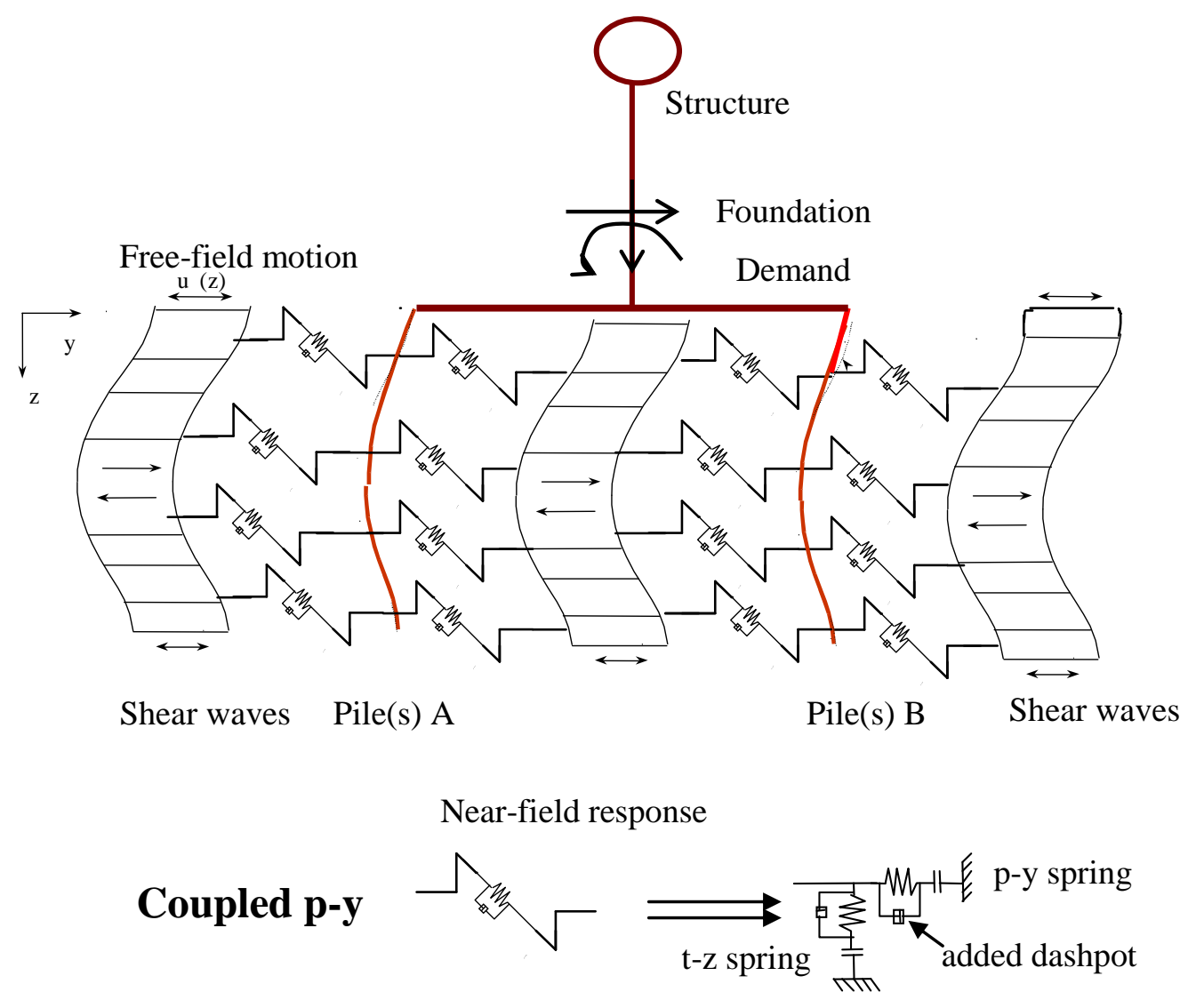

Figure 1 Conceptual representation of pile group response under seismic loading conditions 


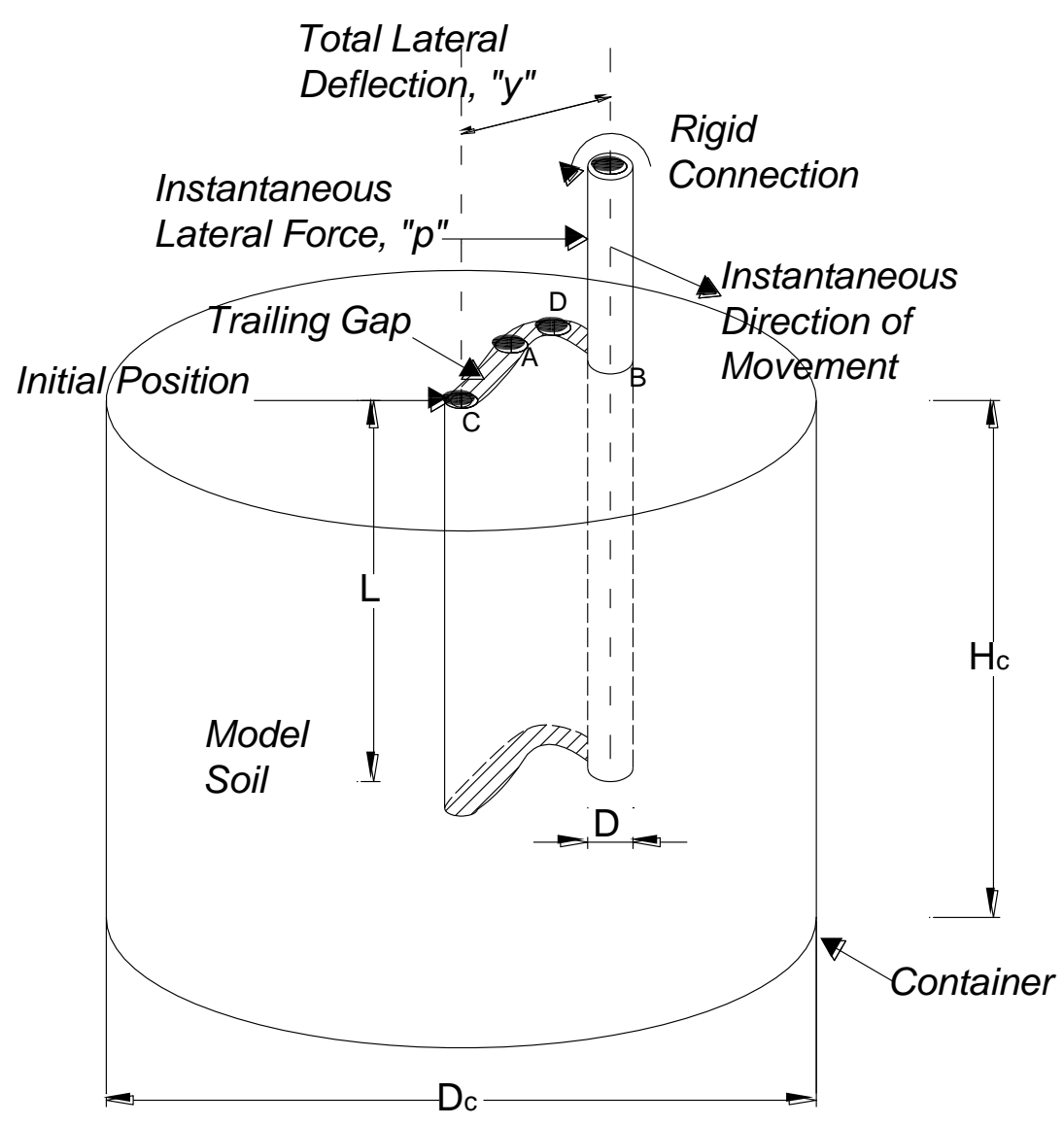

Figure 2 Schematic representation of the multidirectional pot-test 


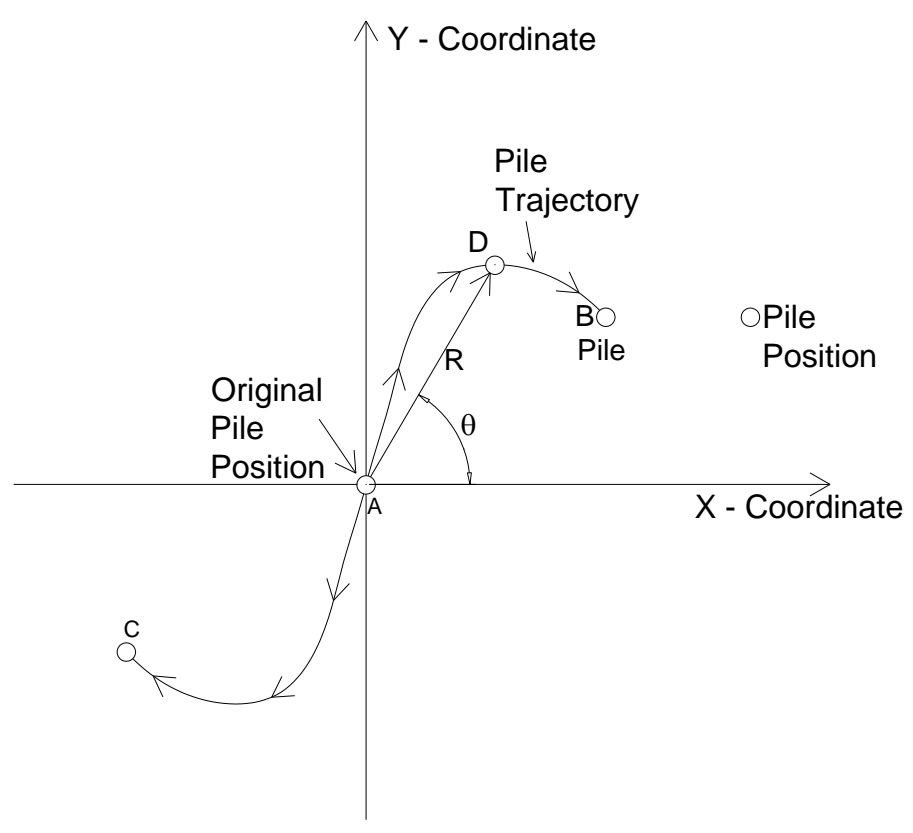

Figure 3 Multidirectional pile transit path

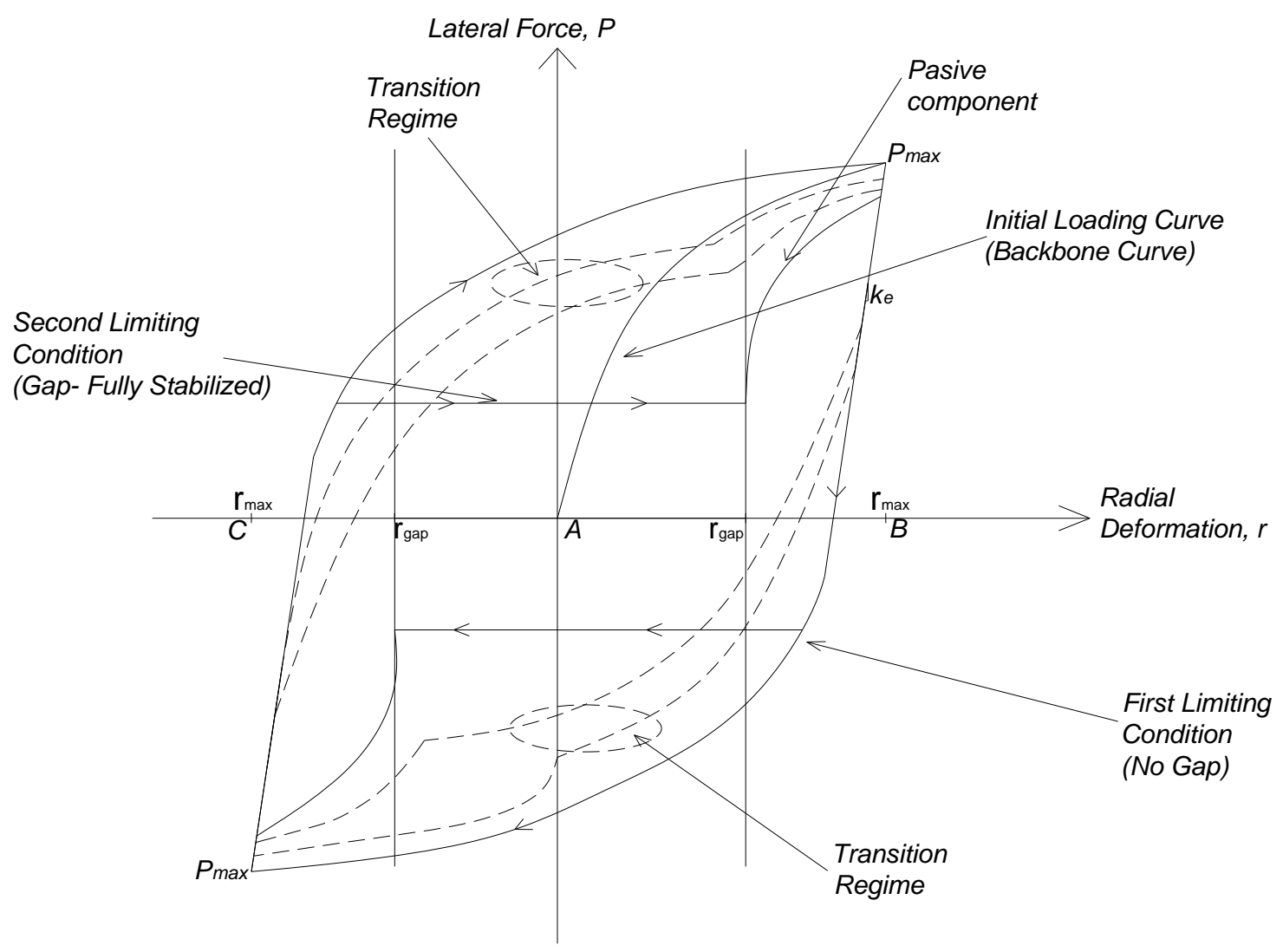

Figure 4 Limiting conditions for analysis and transition regime 


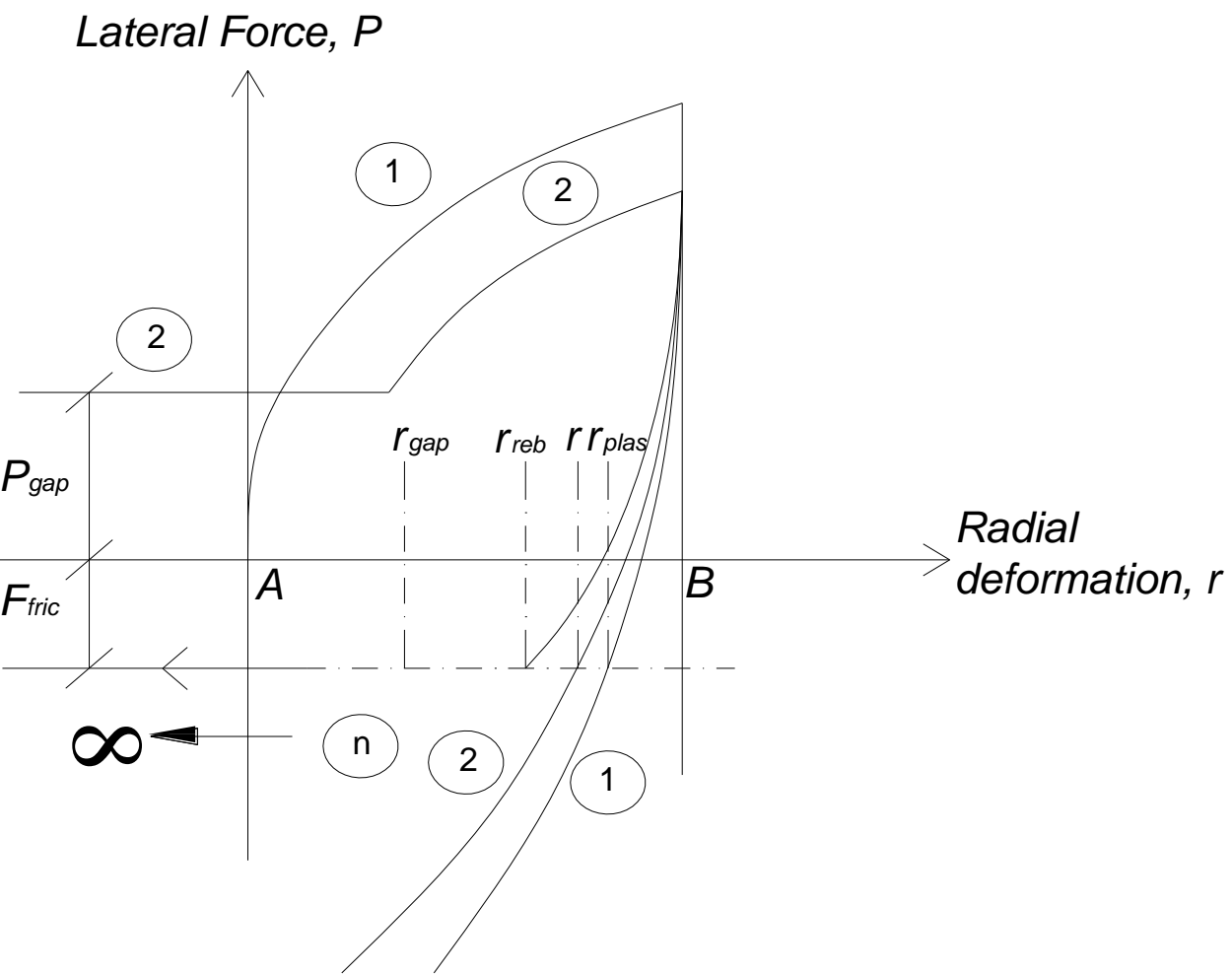

Figure 5 Progressive evolution of the gap 


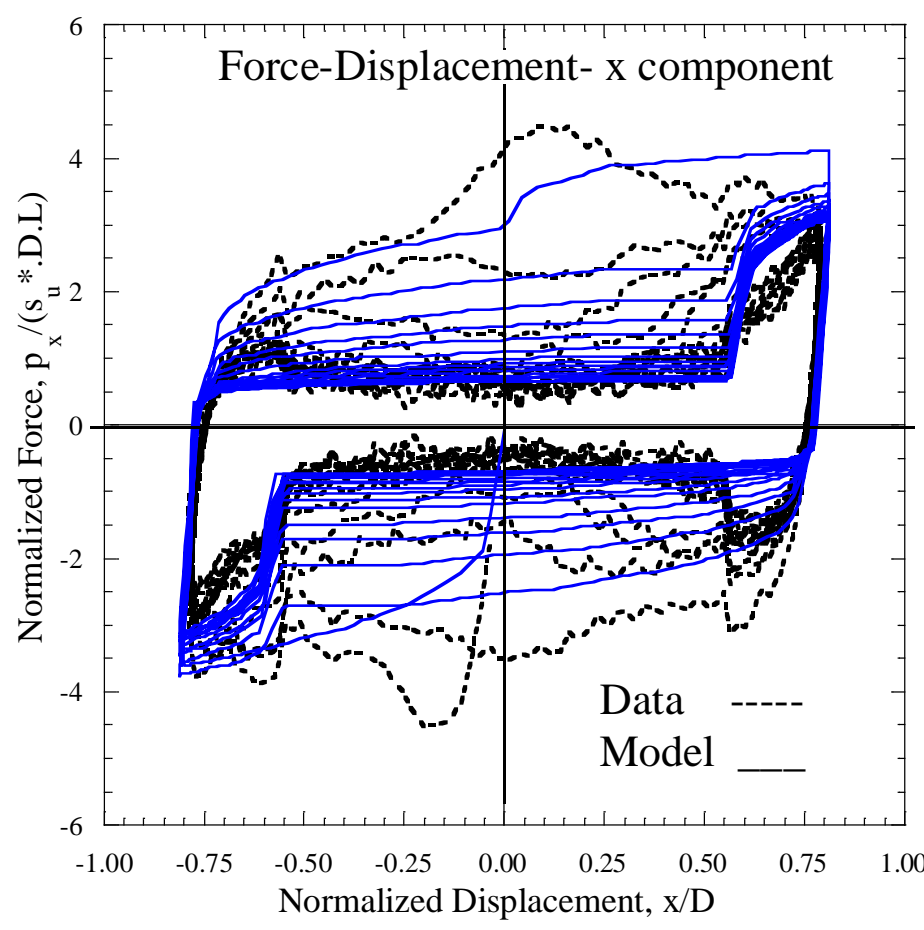

\begin{tabular}{|c|c|c|c|c|c|c|c|}
\hline \multicolumn{5}{|c|}{ TEST INFORMATION } & \multicolumn{2}{c|}{ SOIL PROPERTIES } \\
\hline Test \# & Path & $\mathrm{A}_{\mathrm{x}} / \mathrm{D}$ & $\mathrm{A}_{\mathrm{x}} / \mathrm{A}_{\mathrm{y}}$ & $\mathrm{F}_{\mathrm{x}}(\mathrm{Hz})$ & $\mathrm{F}_{\mathrm{y}}(\mathrm{Hz})$ & $\omega(\%)$ & $\mathrm{s}_{\mathrm{u}}^{*}(\mathrm{kPa})$ \\
\hline 2D858 & LInear & 0.8 & $1: 1$ & 0.1 & 0.1 & 119 & 5.75 \\
\hline
\end{tabular}

Figure 6 Model parameter determination using Uni-directional Linear pile transit path 


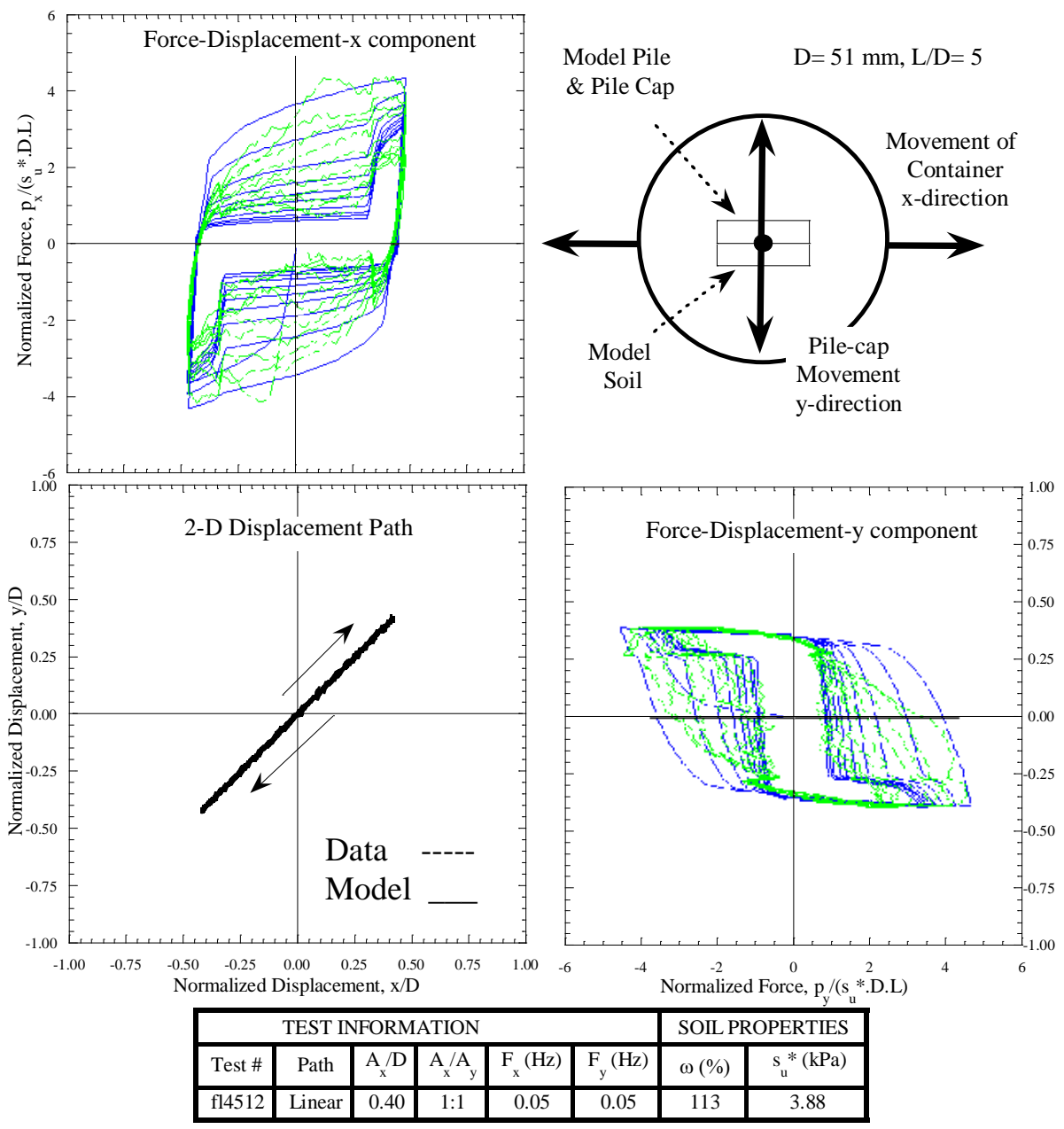

Figure 7 Model prediction and measured response for a linear pile transit path 

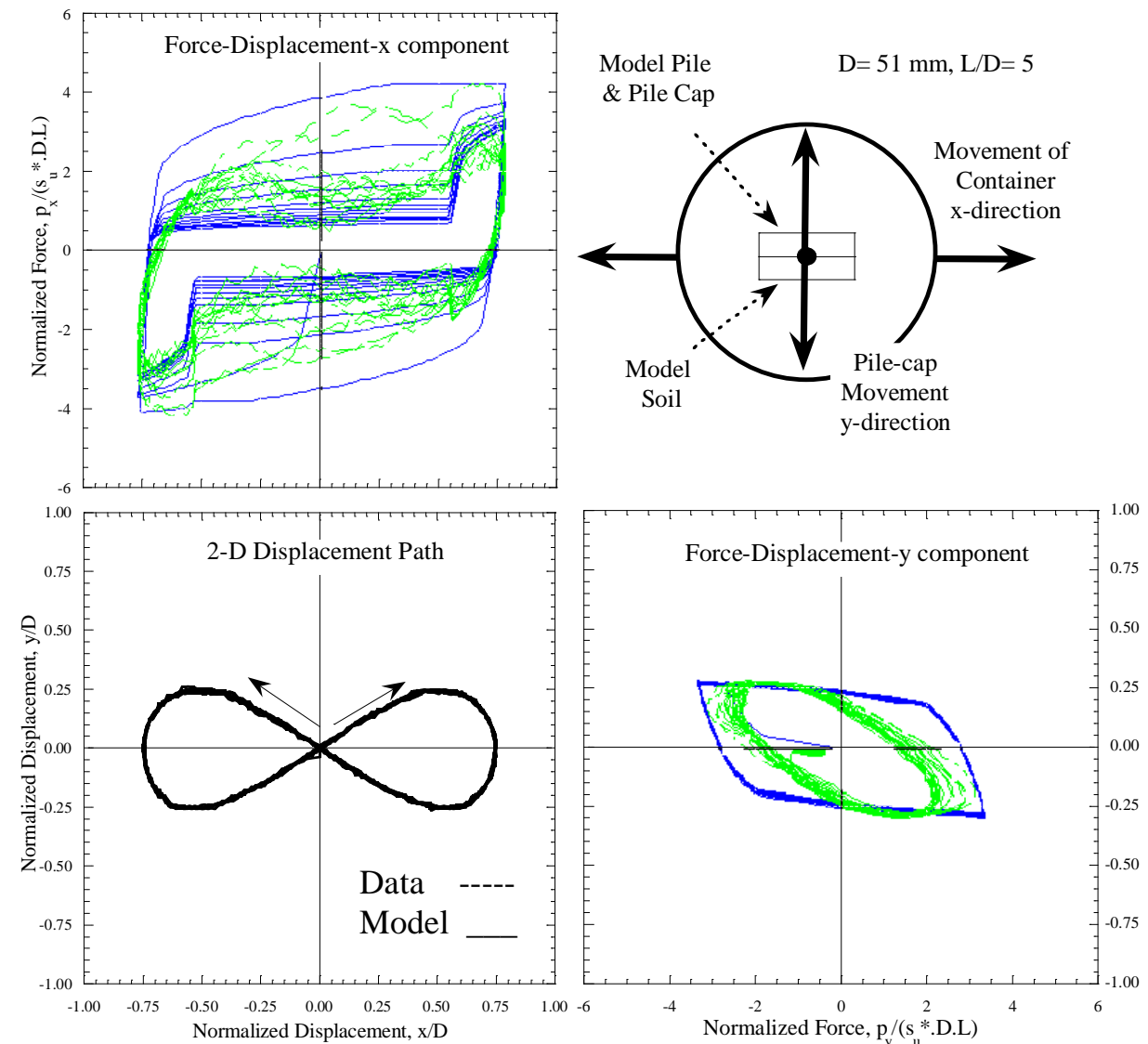

\begin{tabular}{|c|c|c|c|c|c|c|c|}
\hline \multicolumn{5}{|c|}{ TEST INFORMATION } & \multicolumn{2}{c|}{ SOIL PROPERTIES } \\
\hline Test \# & Path & $\mathrm{A}_{\mathrm{x}} / \mathrm{D}$ & $\mathrm{A}_{\mathrm{x}} / \mathrm{A}_{\mathrm{y}}$ & $\mathrm{F}_{\mathrm{x}}(\mathrm{Hz})$ & $\mathrm{F}_{\mathrm{y}}(\mathrm{Hz})$ & $\omega(\%)$ & $\mathrm{s}_{\mathrm{u}}{ }^{*}(\mathrm{kPa})$ \\
\hline $\mathrm{f} 81315$ & Figure 8 & 0.75 & $3: 1$ & 0.04 & 0.08 & 112 & 3.82 \\
\hline
\end{tabular}

Figure 8 Model prediction and measure response for a figure 8 pile transit path 


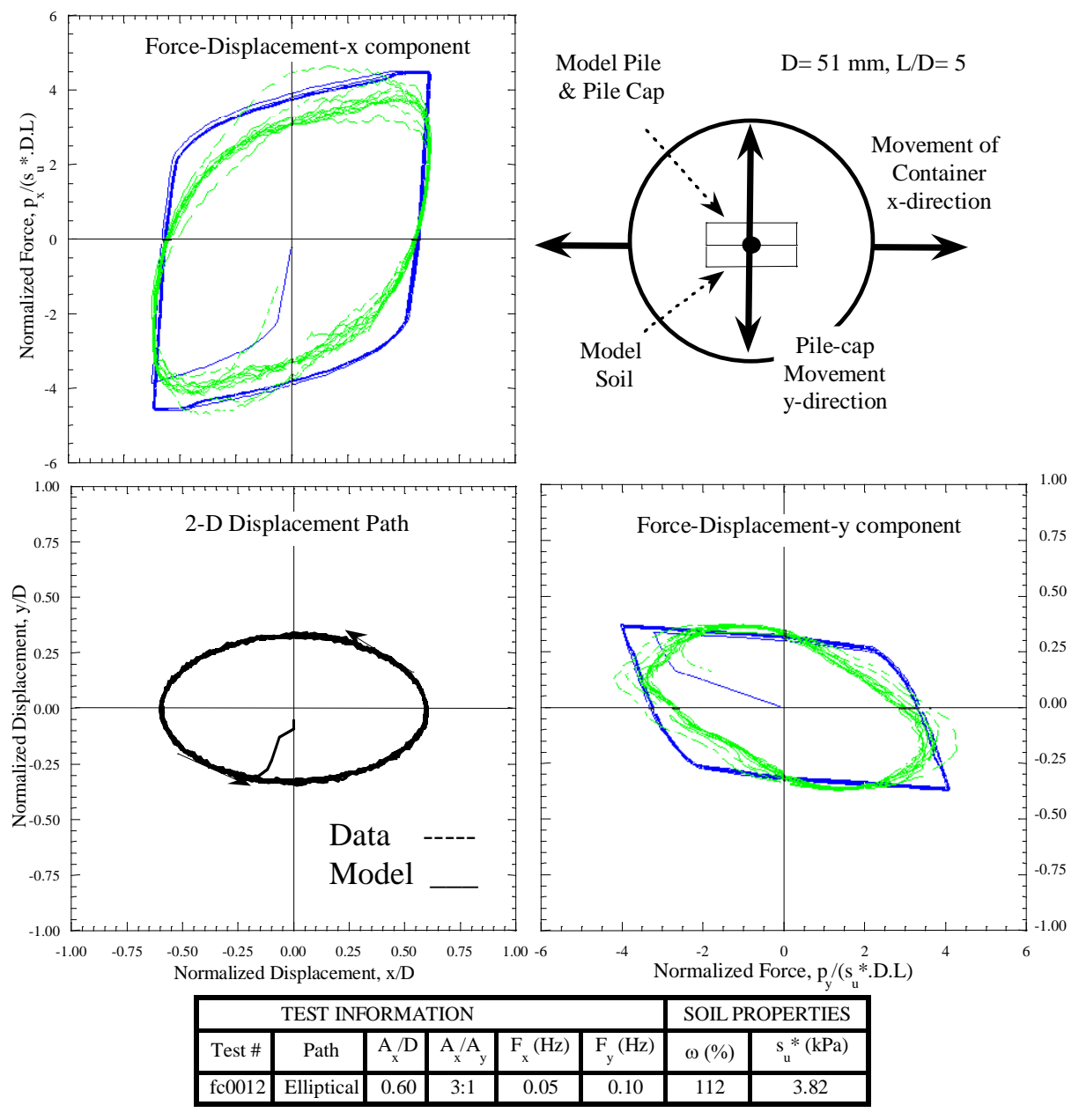

Figure 9 Model prediction and measure response for an elliptical pile transit path 

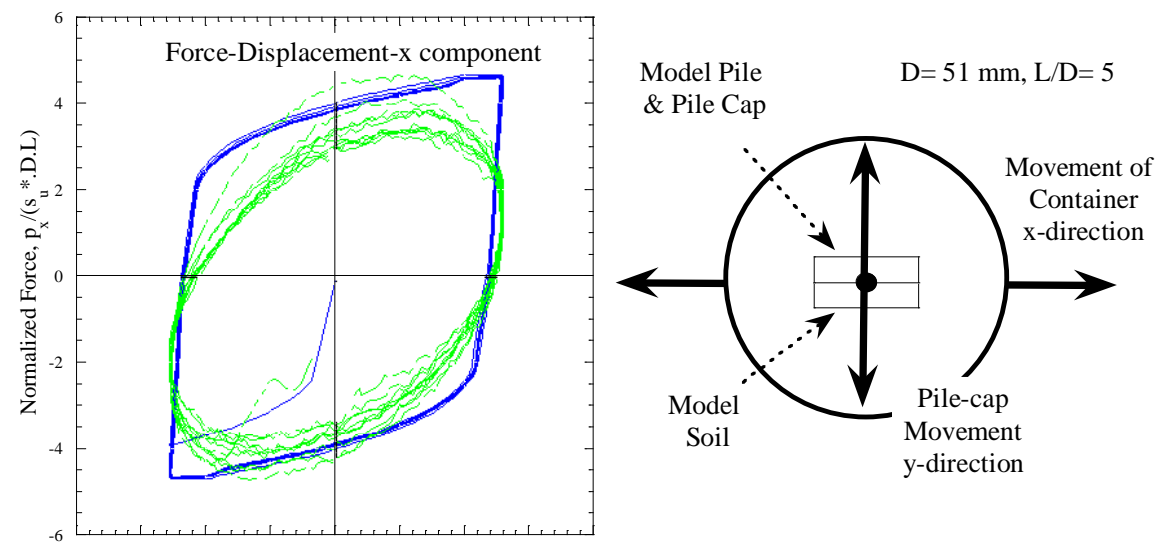

Soil

y-direction
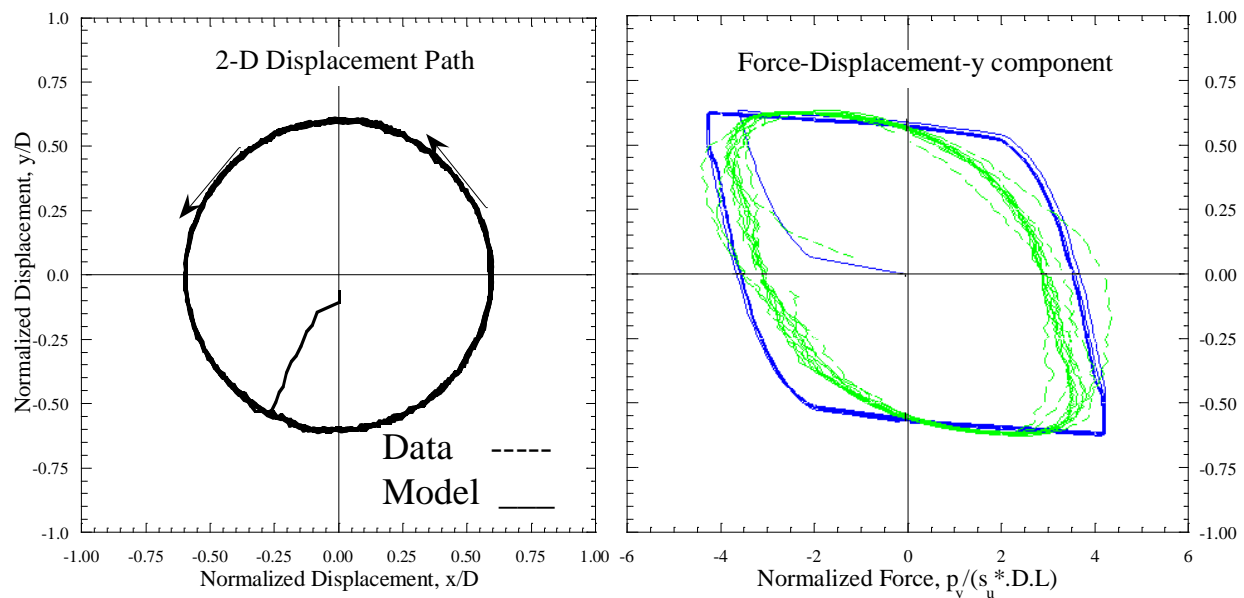

\begin{tabular}{|c|c|c|c|c|c|c|c|}
\hline \multicolumn{5}{|c|}{ TEST INFORMATION } & \multicolumn{2}{c|}{ SOIL PROPERTIES } \\
\hline Test \# & Path & $\mathrm{A}_{\mathrm{x}} / \mathrm{D}$ & $\mathrm{A}_{\mathrm{x}} / \mathrm{A}_{\mathrm{y}}$ & $\mathrm{F}_{\mathrm{x}}(\mathrm{Hz})$ & $\mathrm{F}_{\mathrm{y}}(\mathrm{Hz})$ & $\omega(\%)$ & $\mathrm{s}_{\mathrm{u}}{ }^{*}(\mathrm{kPa})$ \\
\hline fc9012 & Circular & 0.60 & $1: 1$ & 0.05 & 0.05 & 116 & 3.64 \\
\hline
\end{tabular}

Figure 10 Model prediction and measure response for a circular pile transit path 


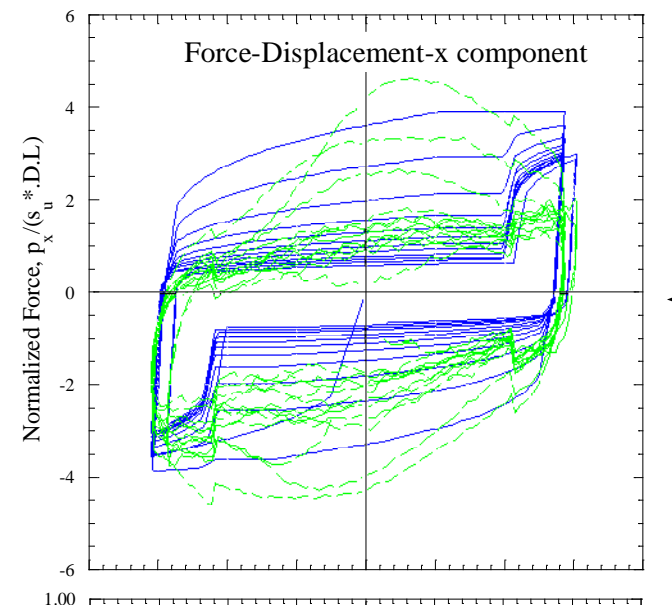

$$
\text { Model Pile } \quad \mathrm{D}=51 \mathrm{~mm}, \mathrm{~L} / \mathrm{D}=5
$$
$\&$ Pile Cap
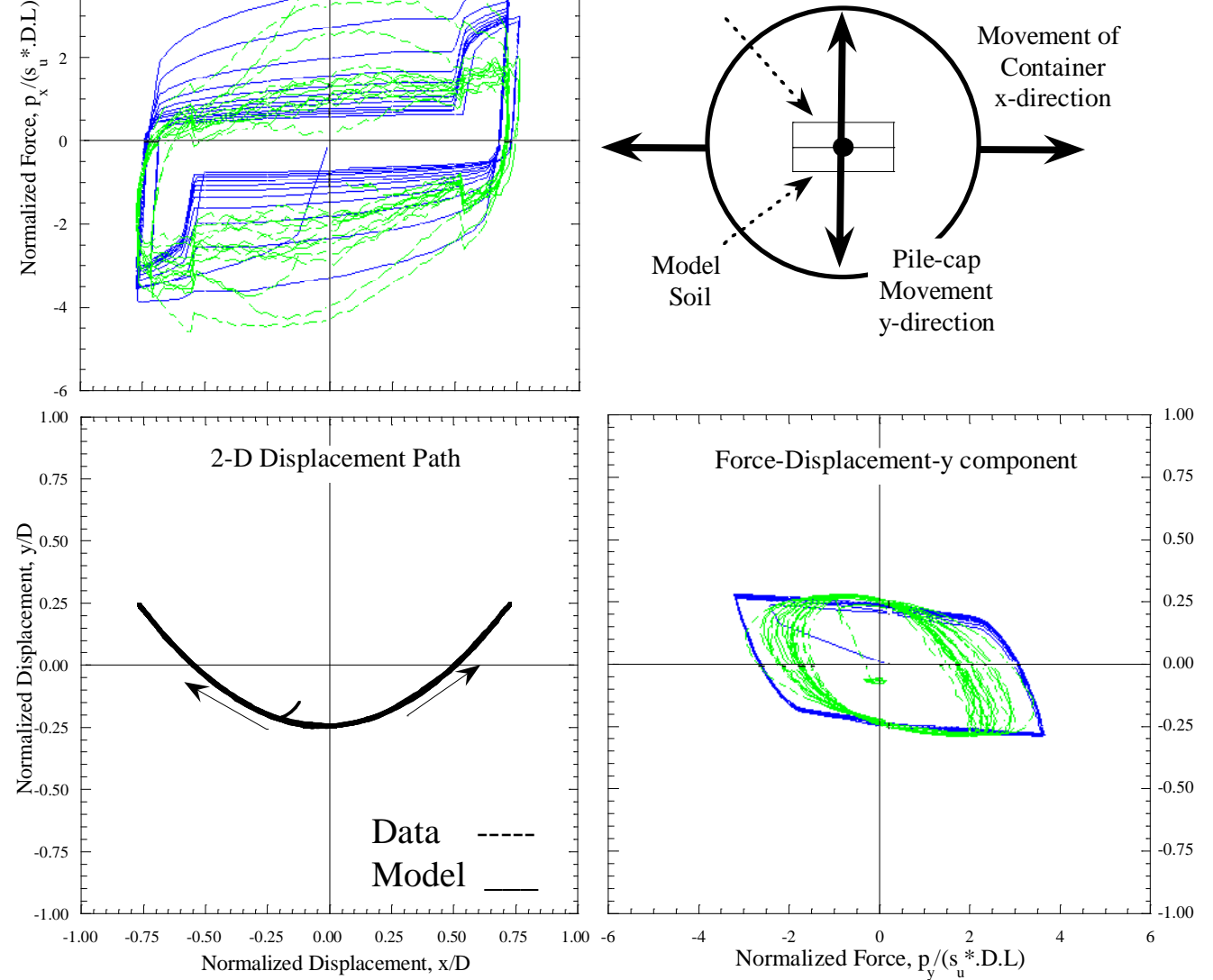

\begin{tabular}{|c|c|c|c|c|c|c|c|}
\hline \multicolumn{5}{|c|}{ TEST INFORMATION } & \multicolumn{3}{c|}{ SOIL PROPERTIES } \\
\hline Test \# & Path & $\mathrm{A}_{\mathrm{x}} / \mathrm{D}$ & $\mathrm{A}_{\mathrm{x}} / \mathrm{A}_{\mathrm{y}}$ & $\mathrm{F}_{\mathrm{x}}(\mathrm{Hz})$ & $\mathrm{F}_{\mathrm{y}}(\mathrm{Hz})$ & $\omega(\%)$ & $\mathrm{s}_{\mathrm{u}}^{*}(\mathrm{kPa})$ \\
\hline f80015b & Parabolic & 0.75 & $3: 1$ & 0.04 & 0.08 & 116 & 3.84 \\
\hline
\end{tabular}

Figure 11 Model prediction and measured response for a parabolic pile transit path 
Table 1. Summary of the Model Parameters

\begin{tabular}{|c|c|c|c|}
\hline Mechanism & Parameter & Description & Value \\
\hline \multirow{3}{*}{ Gap Evolution } & $\varepsilon_{\mathrm{c}}$ & $\begin{array}{c}\text { Defines the Critical } \\
\text { Displacement } \mathrm{y}_{\mathrm{c}}\end{array}$ & 0.05 \\
\hline & $\mathrm{P}_{\mathrm{ult}}$ & $\begin{array}{c}\text { Ultimate Lateral Soil } \\
\text { Resistance }\end{array}$ & $27 \mathrm{~kg}$ \\
\hline & $\mathrm{p}$ & $\begin{array}{l}\text { Defines non-linearity in } \\
\text { the First Loading Curve }\end{array}$ & $3-4$ \\
\hline \multirow{4}{*}{$\begin{array}{l}\text { First Loading } \\
\text { "Backbone } \\
\text { Curve" }\end{array}$} & $\alpha_{\mathrm{f}}$ & $\begin{array}{l}\text { Defines the limiting } \\
\text { value of the lateral } \\
\text { force when the gap is } \\
\text { fully open }\end{array}$ & 0.24 \\
\hline & $\mathrm{K}_{\mathrm{re}}$ & $\begin{array}{c}\text { Defines the Elastic } \\
\text { Rebound after } \\
\text { Unloading }\end{array}$ & 90 \\
\hline & $\mathrm{R}_{\mathrm{fac}}$ & $\begin{array}{l}\text { Defines the Position of } \\
\text { the Gap after Unloading }\end{array}$ & 0.75 \\
\hline & $\mathrm{m}$ & $\begin{array}{l}\text { Defines the gap } \\
\text { evolution with the } \\
\text { number of cycles }\end{array}$ & 0.3 \\
\hline
\end{tabular}

